\title{
Using Contextual Constructs Model to Frame Doctoral Research Methodology
}

\author{
Shirlee-ann Knight and Donna Cross \\ Edith Cowan University, Joondalup, WA, Australia
}

s.knight@ecu.edu.au d.cross@ecu.edu.au

\begin{abstract}
This paper presents a novel research model - Contextual Constructs Model (CCM) and the theory that underpins it - Contextual Constructs Theory (CCT). First developed as part of a complex project investigating user perceptions of information quality during Web-based information retrieval, the CCM is not a single research method per se, but is a modelled research framework providing an over-arching perspective of scientific inquiry, by which a researcher is able to identify multiple possible methods of study and analysis according to the identified research constructs and their contexts. Central to CCM/CCT is that all research involves the fusion of two key elements: 1) context; and 2) cognitively-driven constructs; and that the co-dependent nature of the relationship between these two research components inform the research process and eventual outcomes. The resulting CCM is one that frames research as a contextual process of phases, indentifying the conceptual, philosophical, implementation, and evaluation tasks associated with a research investigation. The value of framing research within a CCM comes from its capacity to frame complex, real world phenomena since its epistemology is a blend of a critical-real world view - where reality can be both constructed and constant; within a systems-science paradigm where constructs are not reduced to isolated parts, but investigated in terms of multiple coconstructions and the contextual relationships between them
\end{abstract}

Note: A shorter discussion (10 pages) of the CCT/CCM described in this manuscript was published as part of the Qual-IT 2010 Conference proceedings (see Knight, Halkett \& Cross, 2010)

Keywords: Critical Realism, Systems-Science, Contextual Constructs Model, Contextual Constructs Theory, Research Philosophy, Research Design, Research Methodology.

\section{Introduction}

"All research is based on assumptions about how the world is perceived and how we can best come to understand it" (Trochim, 2002).

Developing a research methodology for a research project is a complex process (Goulding, 2002; Holden \& Lynch, 2004) replete with a mine-field of choices for the researcher. The complex, of-

Material published as part of this publication, either on-line or in print, is copyrighted by the Informing Science Institute. Permission to make digital or paper copy of part or all of these works for personal or classroom use is granted without fee provided that the copies are not made or distributed for profit or commercial advantage AND that copies 1) bear this notice in full and 2) give the full citation on the first page. It is permissible to abstract these works so long as credit is given. To copy in all other cases or to republish or to post on a server or to redistribute to lists requires specific permission and payment of a fee. Contact HPublisher@InformingScience.orgH to request redistribution permission. ten emotive, and at times seemingly contradictory vocabulary, even of established theory, methods, and applications of methods can often serve to further complicate this process, particularly for the early career researcher.

This paper presents a contextually driven model of research, designed to guide a researcher through the process of developing a research methodology, and 
the model attempts to frame something of the process of research, in an effort to generate thought and discussion which moves beyond the over-simplistic and formulaic principles of 'this' formal versus 'that' formal methodology. The paper then provides a framework by which the researcher is able to embrace the cognitive journey involved with identifying a research problem, formulating a means by which to investigate that problem, and finally developing the research vocabulary by which to describe the research as a whole.

\section{Underlying Theory: Contextual Constructions of Research}

The theory that underpins the CCM is described as 'Contextual Constructs Theory' (CCT) and is offered herein as a novel approach to the overall conceptualisation of a complex research project. Central to CCT is that all research involves the fusion of two key component parts, namely, (1) context and (2) cognitively-driven constructs. Important too is the inherent, informing, and affectual relationship between the two.

\section{Research Context, Research Constructs, and their Relationship}

"From a very early age, we are taught to break apart problems, to fragment the world. This apparently makes complex tasks and subjects more manageable, but we pay a hidden, enormous price... we lose our intrinsic sense of connection to a larger whole." (Senge, 2006)

A research context is the associated entities surrounding the research and researcher such as the following: the discipline of the research project (Trauth, 2001); the phenomenon (also called the research object) being investigated (Remenyi, Williams, Money \& Swartz, 1998); previous theory related to the research object (Webster \& Watson, 2002); the researcher (Fielden, 2003) - including their evolving "research lens" (Trauth, 2001, p. 6); and the conceptualisation of how the research object will be investigated, or research problem (Ellis \& Levy, 2008; Kerlinger \& Lee, 2000).

The second central concept of CCT is that research as a mode of inquiry is constructed. That is, the researcher must find ways to build abstracted constructs that are used to represent or describe the phenomena being investigated. Most often, these constructs are described in language, words that come to represent phenomena that may have existed long before a scientist found a word to describe it. For example, apples have always fallen from trees, yet the scientific community came to know this phenomenon as the force of "gravity" only since Newton (1687) coined a word to represent it. Closer to home, the IS model of the Technology Acceptance Model (TAM) (Davis, 1989), which investigates users' acceptance and adoption of information technologies in various contexts, depicts "user acceptance" in terms of Perceived Usefulness (PU) and Perceived Ease of Use (PEoU). Interestingly, PU and PEoU are themselves constructs, which - like all constructs have their own associated attributes, characteristics, and meanings. So this then is the constructed vocabulary of research; words and concepts that have come to represent meaning within specific scientific contexts and the research constructs are seen as the constructions developed by the researcher to describe and investigate phenomena in the process of conceptualising the research.

Importantly in describing the co-dependent nature of these two central CCT concepts, constructs are seen never to exist outside of a context, which in turn is said to have an inherent influence on the development of the research constructs. It is this contextual approach that places the CCM into a systems science paradigm (as described by von Bertalanffy, 1950) where relationships between constructs are recognised as an integral part of any scientific investigation of complex phenomena (Hammond, 2003). Traditionally, scientists have tended to study small, isolated parts of phenomena. This is done to limit investigative variables (Senge, 2006), decrease ambiguity (Seymour, 2006) and increase validity and generalisability (Lee, 1989). However, this de- 
contextualisation of research objects - in a positivist/reductionist sense - has been found to be of little value when used to investigate complex, interacting phenomena that exhibit the capacity to evolve and change over time since it is the collective interaction of the objects as much as their individual physical properties that determine this 'emergent' behaviour (Kaufman, 1992). For example, the human brain is made up of around ten thousand million nerve cells called neurons, with around one hundred billion connections between them. The emergent behaviours of this complex system of neurons and connections include highly complex phenomena such as human cognition, emotion, sensation, and motion. Significantly, not one single neuron possesses these properties on its own. So CCT provides an over-arching scaffolding for research that requires conceptualisation of both constructs and contexts - ideal for complex, real-world problems. How this process develops is illustrated using the CCM.

\section{Contextual Model: Research as a Process of Phases}

The CCM, illustrated in Figure 1, proposes that it is useful to see the process of scientific inquiry as a journey through four evolving phases: 1) Conceptual; 2) Philosophical; 3) Implementation; and 4) Evaluation.

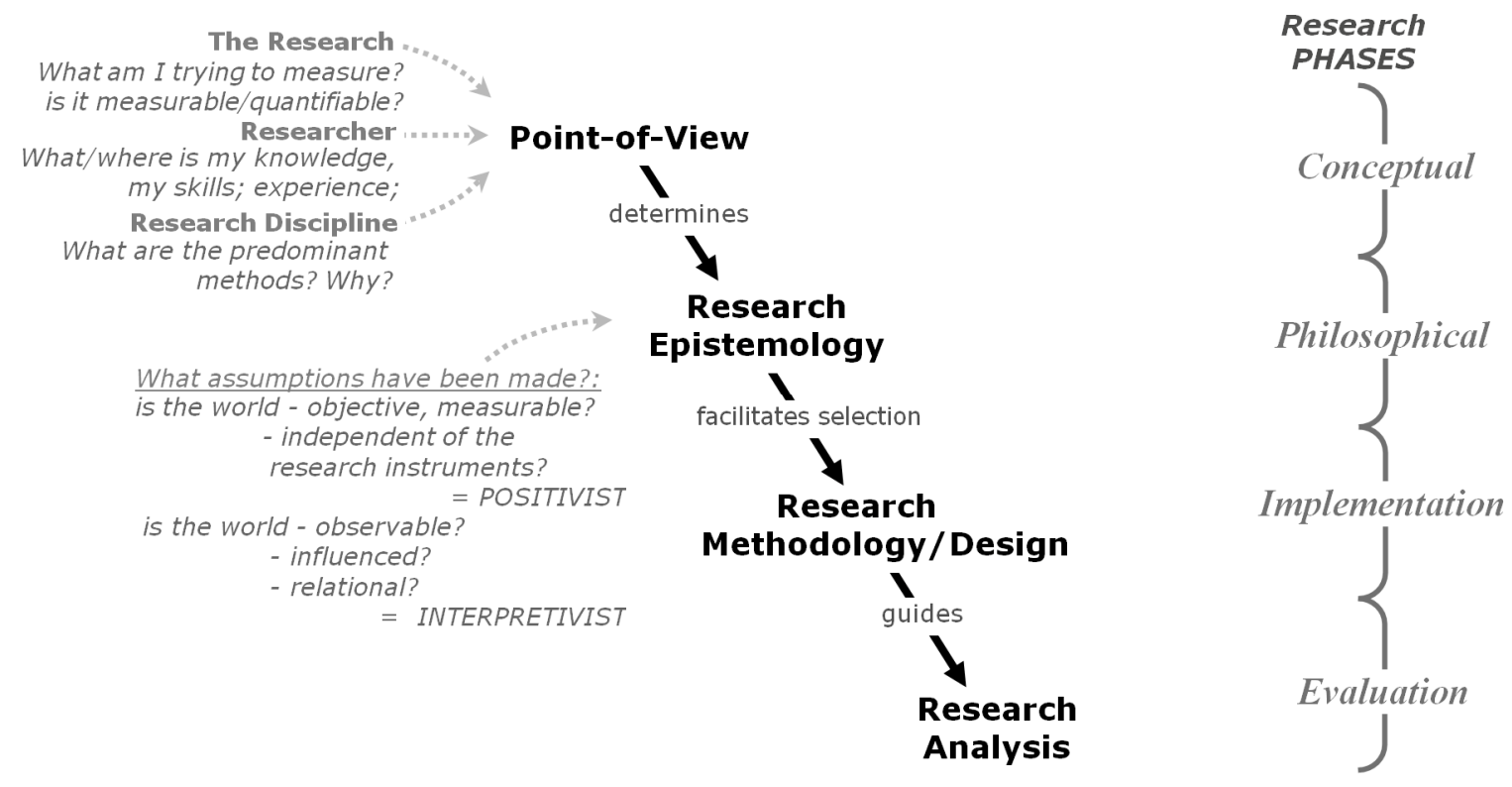

Figure 1. The Contextual Constructs Model

\section{Conceptual Phase: Finding the Research Point-of-view}

Determining the point-of-view of any research is largely a conceptual process. As the starting point of the journey, it involves the researchers identifying exactly what it is that they wish to learn and the context in which they wish to learn it. Within the CCM, this conceptual phase is considered to be of paramount importance since it is where the conceptual validity of the research is established. Remenyi et al. (1998) stated that the primary drivers of research approaches include (1) the topic to be researched and (2) the specific research question(s). Trauth (2001) described these drivers more specifically in terms of being 'influencing factors' and named them as follows: (1) the research problem; (2) the researcher's theoretical lens; (3) the characteristics of the phenomena; (4) the researcher's skill; and (5) the academic politics around the research/researcher. Ellis \& Levy (2009) described the research process as starting with the following: (1) the problem driving the research; (2) the body of knowledge; and (3) the nature of the data. Although described using different terminology, there are essential commonalities in the 
proposed schema, and the CCM conceptualises these similarities into three elements which collectively establish the research point-of-view.

1. The Research - phenomena characteristics (including the nature of the data Ellis \& Levy, 2009) and research problem (Trauth, 2001; Ellis \& Levy, 2009), research topic and questions (Remenyi et al., 1998);

2. The Research Discipline - academic politics and researcher's theory lens (Trauth, 2001), and body of knowledge (Ellis \& Levy, 2009);

3. The Researcher - researcher skill and researcher lens (Trauth, 2001)

\section{The research: (Phenomena \& questions)}

"what one wants to learn determines how one should go about learning it" (Trauth, 2001).

\section{The research phenomena/objects}

Determining the key characteristics of the phenomena being investigated is a fundamental first step towards developing a model to guide how the research can be conceptualised. In a contextual, systems-science approach, this activity includes identifying whether the major research object is one phenomenon possessing a range of characteristics or a set of phenomena possessing their own as well as relational characteristics (Miller, 1978).

In addition to informing the researcher regarding any relational contexts of the research object(s), the growing understanding of the phenomena informs the research process in two ways:

1.) It indirectly drives the intangibles of the research, such as the research philosophy, as the researcher makes conceptual decisions about the nature of the phenomena, the nature of their relationship to or with the phenomena, and the nature of the world.

2.) It directly drives the tangibles of the research, such as, What is being measured? How can it be measured? The answers to these tangible considerations - i.e., Can the research object be observed? Quantified? Defined? Contextualised? - form the basis of the research problem to be investigated and help shape the research questions and objectives developed for the project

\section{The research questions}

Conceptualising and articulating the research questions or objectives helps focus the scope of the research (Eisenhardt, 1989; Heinström, 2003; Kari, 2004; Tashakkori \& Creswell, 2007), thereby helping the researcher to do things such as the following:

1.) determine key characteristics of the phenomenon to be investigated during the project;

2.) identify key areas of literature needed to fully investigate the research problem, including previously used methodologies used for similar investigations;

3.) identify a discipline context of the research, as well as areas of synergy related to the phenomena investigation across multiple disciplines;

4.) identify the type of data to be collected; and

5.) determine a target user-population (where applicable).

The most robust research questions are ones that both assume and imply more than what they explicitly state. For example, the research question "How do individual users apply common perceptions of information quality to make judgments about the information they retrieve from the World Wide Web?" (Knight, 2008, p. 131) assumes that (1) users have pre-existing perceptions of 
what constitutes information quality, (2) users engage these perceptions to judge the usefulness of information they wish to retrieve from the Web, and (3) users' engagement of their Web-IQ perceptions will be manifest and, therefore, be observable in their Web information retrieval attitudes and behaviours. The question also implies that users probably have a choice regarding where they retrieve their information, and how they use their perceptions of information quality to retrieve information may vary dependent on the environment, hence the assumption in \#3 that users will engage Web-specific perceptions of IQ.

The implications and assumptions associated with the research questions are what give those questions their depth, and it is important the researcher carefully examine the assumed and implied aspects of each question (Alvesson \& Sandberg, 2011; Donham, Heinrich \& Bostwick, 2009 ) to ensure a robust understanding of what is being investigated (Sandberg \& Alvesson, 2011). In the previously illustrated question, for example, the underlying questions being asked include (a) What is information quality? and (b) How do individual differences among users act as antecedents in the process of user perceptions of information that is 'fit-for-use'? (Wang \& Strong, 1996) The "individual differences" among users can then be conceptualised in terms of user-demographic or user-task factors, such as 'user experience' with Web technology or 'information task' (what the user is searching for), and used to analyse and/or categorise differences in participant results.

\section{Research discipline: (Discipline context)}

The purpose of identifying the research discipline context of a research project is twofold:

1.) It helps identify key areas of research for the essential literature review (Trauth, 2001; Webster \& Watson, 2002); and

2.) It provides a methodological context for the research - where the researcher is able to identify key methodologies commonly used for similar types of research (Levy \& Ellis, 2006).

The examination of previous theory as it relates to a discipline context should be multi-level, taking in discipline, phenomena, and methodology considerations. For example, the researcher can explore general methodologies associated with his or her discipline, as well as a more focused exploration of the methodological approaches used previously to investigate the identified phenomena across multiple disciplines. Figure 2 illustrates the types of researcher considerations at this foundational phase of any research.

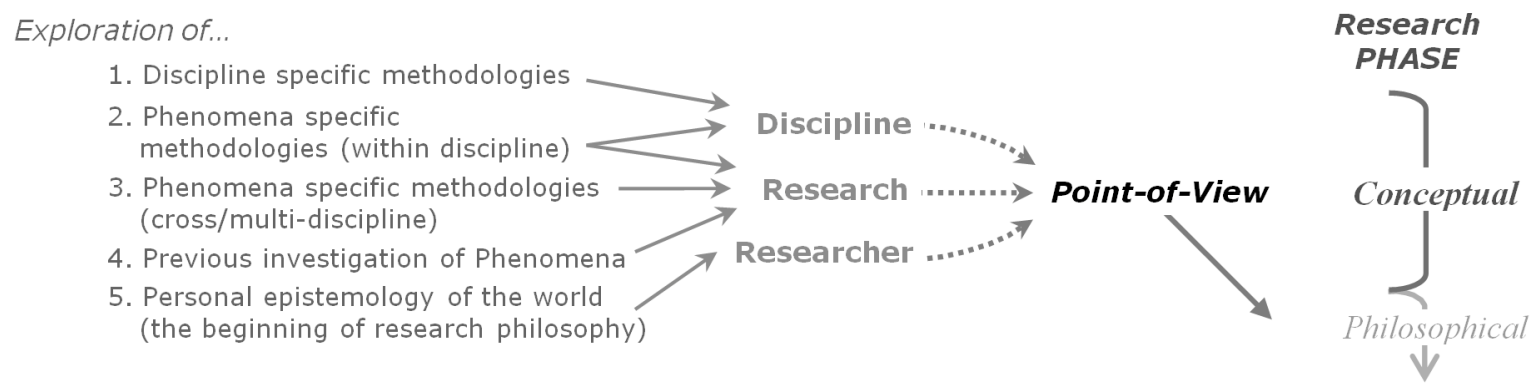

Figure 2. Contextual Constructs of Research Detail (influences on Point-of-View)

An important characteristic of research, as the CCM conceptualises it, is that although its ultimate outcome is founded on logic, which can be considered relatively linear, research is a process involving personal cognition, and cognition is anything but linear (Leonard, Scholl \& Kowalski, 1999; White, 2007). This means that, although - for the sake of clarity - the process is described here in what amounts to a linear description, identified parts of the process (see Figure 1) take 
place in a relatively mutable order - with subtle differences between researchers and/or research projects. In addition, as the researcher, as well as the research, develops and grow in sophistication, some parts of the research process can be iteratively revisited.

\section{The Researcher: (Positioning the "self" - Considerations of philosophy)}

Within the CCM, the factors that relate to the researcher as a 'self-driven' cognitive entity in their own right and their influence on the research project's 'point-of-view' are what Trauth (2001) described as the researcher's developing "theoretical lens" (p. 6) and "skills" (p. 8). Fielden (2003) described the involvement of a researcher's own influencing point-of-view as "inevitable" (p. 127). Inevitable because a researcher's own individual mind-set, bias, skills, and knowledge become an intrinsic part of the research process (Janesick, 2000). To the 'positivist' researcher, such an acknowledgement is unpalatable, given their pre-research supposition that a researcher must (and can) remain neutral in the process of research collection, observation, and analysis. In this way, the positivist attempts to remove his or her 'self' from the study and in so doing, makes a claim to a more 'objective' research approach. From a purely pragmatic standpoint, however, 'critical' and 'interpretivist' researchers recognise that the researcher is part of the world being studied (Krieger, 1991; Olesen, 2000; Schostak, 2002). Moreover, the act of the research investigation itself has the capacity to affect what is being researched, which, in turn, has the capacity to influence perceptions of the phenomena and therefore interpretation of results.

Trauth (2001) names two researcher-driven influencing factors, namely, the researcher's theoretical lens and the researcher's skill, and, Schostak (2002) contended, the very act of researching can, and does, have an effect on these two characteristics. The CCM recognises that as researchers envelope themselves in the theory and academic literature associated with their discipline and the phenomena being studied, they can expect to become more knowledgeable and, therefore, continually adapt and refine their theoretical lens. The same can be said of a researcher's skill. The act of researching (controlling research boundaries, determining methodology, developing data collection tools, collecting data, analysing the data, recognising limitations, and formulating conclusions) has the accumulative affect of improving a researcher's skill. It stands to reason then, and is presupposed by the CCM, that no researcher would expect to be in the same cognitive-space at the end of a research project as at the beginning.

\section{Philosophical Phase: The Research Epistemology}

"The alternative to philosophy is not no philosophy, but bad philosophy.

The 'unphilosophical' person has an unconscious philosophy, which they apply

in their practice - whether of science or politics or daily life" (Collier, 1994, p. 17).

In research terms, epistemology describes the assumptions researchers make about their knowledge of reality and their beliefs regarding how they come to obtain or understand that knowledge. The underlying thought being that the way a researcher perceives the world, to a great extent, determines his or her philosophical assumptions about that world (Myers, 1997) and the constructs and phenomena within it. The CCM contends that it is important to understand what these assumptions are (Cecez-Kecmanovic, 2001; Stahl, 2005). Collier's (1994) contention that "the alternative to philosophy is not no philosophy, but bad philosophy" (p. 17) serves to remind the researcher that not being aware of his or her philosophical assumptions does not mean those assumptions do not exist. In addition, awareness of one's philosophical assumptions does not give a researcher the licence to produce known-bias in his or her research. Instead, this awareness should allow researchers to recognise particular bias in the research and, therefore, limit its influence on the validity of the research as a whole (Dey, 2002). 
The process of building and determining the research point-of-view acts as a sound antecedent to researchers recognising their research philosophy, i.e., their philosophical assumptions about the constructs they will engage during their research. This linear relationship between point-of-view and philosophy was supported by Galliers (1992) who proposed that research assumptions are made transparent when examined, or developed, in the context of a researcher's awareness of either (1) the phenomena to be studied or (2) the goal of the research. The logical relationship between the researchers' understanding of their phenomena and their philosophical assumptions is made explicit in the CCM. However, a linear, or causal, relationship between the research 'goal' (defined by Galliers, 1992, as theory testing, building/extension) and epistemology is not apparent. Indeed, the relationship between philosophy and research goals is depicted in the CCM as being the reverse of Galliers' assertion. That is, philosophical assumptions are seen as being the driver of whether the research ends up being deductive theory testing, inductive theory building, or even a combination of the two.

\section{Research point-of-view to research philosophy}

In the CCM the relationship between research point-of-view and philosophy are of central importance to the conceptual validity of the research. For example, a research project might set out to investigate "the effects of multiple information systems environments on an organisation's ability to manage corporate information." The philosophical assumption that "multiple software systems are less-efficient than one organisation-wide, shared system" would facilitate a completely different research project than a project driven by the philosophical assumption that "multiple systems of communication are normal and an accurate reflection of the complex way humans share information". Figure 3 illustrates how philosophical assumptions can drive the epistemological framework of research and so facilitate the whole research approach, purpose and methodologies.

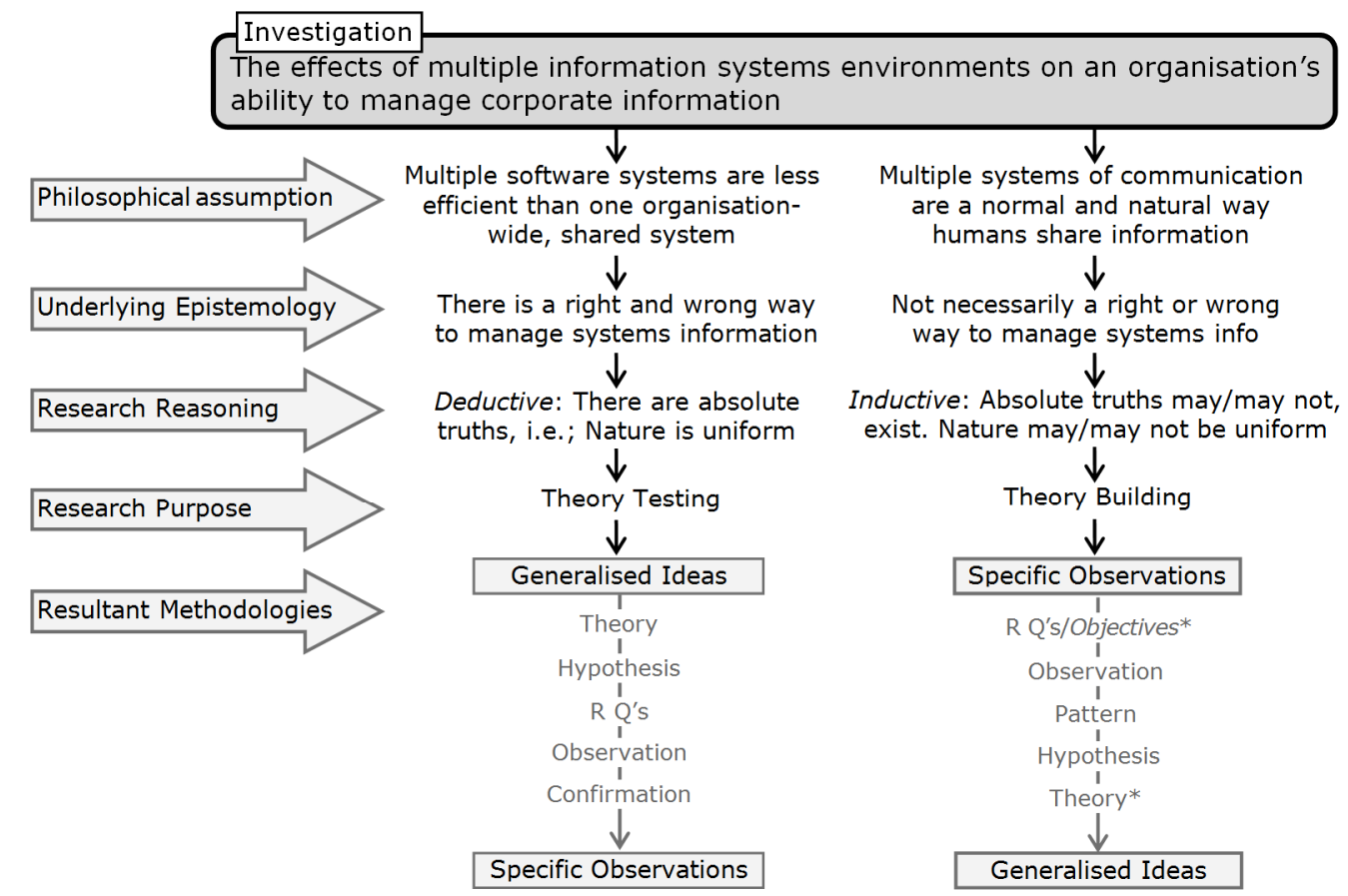

* The term "theory" is used here in a generic sense, to describe the generating of new ideas.

Research Objectives are italics as they may evolve during the project, not necessarily at beginning

Figure 3. The Influence of Philosophical Assumptions on Research Process \& Tasks A note of caution: categorising of the research purpose in terms of theory testing versus theory building, as illustrated in Figure 3, while extremely useful in helping a researcher identify his or 
her epistemological position, is considered by some authors to be unnecessarily limiting (see Kaplan \& Duchon, 1988; Onwuegbuzie \& Leech, 2005; Presbury \& Fitzgerald, 2006; Sonnenwald \& Iivonen, 1999; Thurmond, 2001; Williamson, 2006) in that it locks the researcher into relying on only one research paradigm, or view of reality. This is particularly relevant to the critical researcher, whose position regarding 'reality' can be pluralistic. In addition, polarising the two positions to such an extent implies that a researcher cannot, or should not, mix research methods associated with different paradigmatic views of the world (Onwuegbuzie \& Teddlie, 2003). There is a growing number of researchers who believe that not only is a mixed methodology possible, for some complex research problems it is, in fact, desirable (Christie, Rowe, Perry, \& Chamard, 2000; Dooley, 2002; Greene \& Caracelli, 2003; Knight \& Halkett, 2010; Krauss, 2005; Ramsay, 1998; Thurmond, 2001; Williamson, 2006).

\section{Epistemological pluralism}

Trochim (2002) wrote that "all quantitative data is based upon qualitative judgments; and all qualitative data can be described and manipulated numerically", a notion that suggests quantitative/deductive and qualitative/inductive research approaches are merely two sides of the same coin. This concept is embraced philosophically by pluralism and methodologically by triangulation. Essentially, triangulation is the act of combining various methodologies from both positivist and interpretivist epistemologies (Amaratunga, Baldry, Sarshar \& Newton, 2002; Modell, 2005) and is advocated by researchers who believe that deductive and inductive research are not necessarily opposed but, rather, can be used to focus on different dimensions of the same phenomenon (Das, 1983; Mathison, 1998; Onwuegbuzie \& Leech, 2005). Using this frame of reference, Lee (1991) suggests that positivist and interpretivist approaches are neither opposed nor irreconcilable. At their most basic fundamental level, research approaches are driven by the same need to scientifically understand or explain observed phenomena, which motivates a scientific inquiry of that phenomena. A positivist approach to research is said to begin with a hypothesis which leads to the researcher adopting methodologies designed to test if the hypothesis is true. An interpretivist approach, by comparison, begins with the researcher adopting a methodology designed to more closely observe and analyse the phenomena and develop possible explanations regarding its characteristics. Epistemological pluralism embraces both quantitative/deductive and qualitative/inductive research approaches by supposing that both approaches have degrees of the other inherent within them (Amaratunga et al., 2002).

The argument for developing mixed research approaches is countered by writers like Orlikowski \& Baroudi (1991) who believed that triangulation of methodologies is not possible. For the interpretivist researcher, "There is no sense in which the interpretive perspective can accommodate positivistic beliefs. Interpretive research is seen to be based on philosophical assumptions which are essentially different from those of the positivist perspective" (p. 16). And, for the positivist researcher, there remains what Hume (cited in Rosenberg, 1993) called 'the Problem with Induction', described in terms of a research assumption of the 'uniformity of nature' (Wood, 2000). The 'problem with induction' does not so much come from there being an actual problem with inductive logic or reasoning per se. Indeed, inductive reasoning is critical to the 'this-thereforethis' probability arguments so central to scientific research. To cite a classic example, "this ice is cold" therefore "all ice is cold" is typical inductive reasoning. The problem, as a positivist would see of interpretivist research, is that induction - said to be the reasoning approach of the interpretivist researcher - relies on there being a degree of uniformity to nature, which is not the epistemological underpinnings of interpretivism. And so there remains, at least from the positivist's perspective, an irreconcilable chasm between the interpretivist epistemology and their research reasoning approach. Hume's "Problem with Induction" is an important factor in why CCT and CCM are driven epistemologically by the pluralistic 'Critical Realism', placing the model within a relatively post-positivist paradigm. 


\section{Critical realism}

Central to the CCM, and the CCT that drives it, is that triangulated methodology is an outcome made possible only when a pluralistic epistemology, such as 'Critical Realism', is embraced. A growing area within the Information and Systems Sciences, Critical Realism, like triangulation, embraces the concept of methodological pluralism (Landry \& Banville, 1992), but it does so at a philosophical level by drawing its epistemology from such schools of thought as positivism, interpretivism, and critical research. This is illustrated clearly in the philosophical assumption presented in Figure 3 as driving the interpretivist epistemology (right column). The statement " $m u l$ tiple systems of communication are normal and a reflection of the natural way humans share information" still leaves room for an 'ordered' view of the world in that it does not state the "natural ways humans share information" to be a system devoid of order. In this way, although critical researchers believe that bias is an inherent characteristic of human inquiry (Pather \& Remenyi, 2004), it would be an error to categorise critical research as a purely interpretive approach to research. This is because, for the realist, reality itself is not just a social construct (as an interpretivist would believe) since it is able to pre-exist the social analysis of it (Dobson, 2002). For the critical realist, only the knowledge of reality is inherently subjective, reality itself can remain relatively objective and unchanging. The belief - that there exists a natural uniformity to 'reality' outside of the researcher's contextual interpretation of it - allows the critical researcher to better address Hume's "problem with induction" by assuming degrees of scientific predictability in the phenomena being investigated. For this reason, critical realism, as a research epistemology, more or less requires a pluralistic approach to its adopted methodologies in that it embraces both the absolutes of positivism and the recognised bias of interpretivism. In this context, CCT and CCM provide a much needed means for conceptualising those research phenomena complex enough to require consideration of pluralistic or mixed method approaches.

\section{Implementation Phase: Research Methodology \& Design}

The critical realist epistemology driving the CCM facilitates the development of approaches aligned with both quantitative and qualitative research, providing a rich tapestry of research methods and tools which may otherwise not be available should a researcher take an absolute positivist or interpretivist approach (Mingers, 2001a, 2001b). Specifically, in the context of the original research (see Knight, 2008) which first drove the development of the CCM, the model was used to develop a method to both qualitatively and quantitatively analyse relatively large amounts of quantitative data. The examples of methods, design, and analysis used in the following sections of this article are from that original project. It should be noted that the examples are used to illustrate general concepts within the CCM, rather than provide specific (and only) procedures available to the researcher.

\section{Methodology \& validity}

At an operational level, a research methodology refers to the procedural framework within which the investigation is conducted (Remenyi et al., 1998). It is the use of specific methods to:

1.) Gather adequate and representative evidence of phenomena (Buckley, Buckley, \& Ching, 1976);

2.) Develop appropriate ways to analyse collected data (Fielden, 2003); and

3.) Demonstrate the validity or reasonableness of any findings or conclusions (Amaratunga et al., 2002)

There is an abundance of data collection, collation, analysis, methods, and strategies available to researchers. Some suit specific philosophical approaches better than others, but many can be used, albeit in different ways, with any research purpose. Moreover, some approaches allow, or 
even require, multiple methodologies to be applied. The guiding principle should always be to ensure that the research data retains its validity to the research project (Rowley, 2002). While the term "validity" has most often been associated with more positivist/deductive research, the concept and necessity of validity is central to all research. It is the characteristic by which research can be judged as valid, reliable, and - where appropriate - generalisable. Traditionally, there are four possible levels of validity that a researcher may wish to establish (Dooley, 2002; Pandit, 1996; Rowley, 2002):

1.) Construct validity - is established through the correct design and use of data collection tools for the specific concepts being studied. This is particularly important when a researcher chooses to construct additional or secondary data from the primary data (Slater $\&$ Atuahene-Gima, 2004), such as the creation of 'categories' from existent data used to create new 'units of analysis' within the original data;

2.) Internal validity - is required if the researcher wishes to demonstrate any relationships between parts of the phenomena and is also helpful when replicating a study;

3.) External validity - is required if a researcher wishes to establish a level of generalisability regarding the findings of the research;

4.) Reliability - is established by using a credible and consistent line of enquiry and data collection, that is, that the use of the same data-collection would produce the same results in a similar setting.

In addition to subscribing, where appropriate, to the above types of validity, the CCM/CCT presents the argument that proper consideration of the philosophical assumptions of the research will ensure a fifth level of validity, that of:

5.) Conceptual validity - is achieved when both the constructs of investigation and any philosophical assumptions made there-of are acknowledged and understood in the context of their study.

The paper notes that not all levels of validity are achievable, or necessary, for all research (Dooley, 2002; Rowley, 2002). For example, research that is not trying to establish a relationship between any of the phenomena being studied does not necessarily require internal validity. In the same way, a highly interpretive case study that is seen by the researcher as a 'one-off' - and therefore not requiring the findings to be generalisable - does not necessarily require external validity. It is the contention of the CCM however, that Conceptual validity and Construct validity are absolutely essential to all research if the findings are to be considered valid and reliable, even within their own unique context.

\section{Matching the methodology to the research}

The CCM is not a single Research Method. It is a modelled framework and over-arching approach to scientific investigation by which a researcher is able to identify multiple possible methods of study and analysis according to the identified research constructs and their contexts. In this way, CCT and CCM can be considered a systems approach to scientific inquiry in that both the research objects and the contextual relationships between the objects can become named Constructs of Investigation (CoI). In addition, previous theory is able to play an important role in both the conceptualisation and contextualisation of CoI's. These named constructs are described in the $\mathrm{CCM} / \mathrm{CCT}$ as "Contextual Constructs".

The concept of contextual constructs is not new, but its explicit description as a generic classification object within a broad research model is novel. In addition, its methodological application to either (1) the research object(s), (2) the relationship between objects, or (3) the emergent characteristics in the conceptual space between the objects and relationships make it an extremely useful 
framework for conceptualising research projects designed to investigate complex and multicontextual social phenomena.

Complex methodologically-driven theories and research approaches such as Grounded theory (Glaser \& Strauss, 1967; Strauss \& Corbin, 1994), Case Cluster Method (McClintock, Brannon, \& Maynard-Moody, 1979), Triangulation (Denzin, 1978), Multiple Case Studies (Yin, 1981; Zach, 2006), Theory Building (Eisenhardt, 1989), Constructivism (Jonassen, 1991), Constructivist Grounded Theory (Charmaz, 1995, 2000), Social Constructionism (Gergen, 1999), Ethnography (Geertz, 1973), and Phenomenology (Schutz, Walsh, \& Lehner, 1972) all advocate the supposition of the complex, multi-dimensional, and multi-contextual nature of research objects/phenomena and argue for the adoption of multi-dimensional investigation methods. The CCM provides a framework for this type of research, which places the CCT/CCM squarely into the qualitative methodologies camp. This paper contends, however, that the model/theory's ascription to a critical realism epistemology means it can be appropriated to quantitative and mixedmethod research as well, of which the thesis (see Knight, 2008) and some research (see Knight, 2011; Knight \& Burn, in press) from where the model came, are examples.

\section{Multi-level investigation: An application of CCM to research methodology \& design}

Many research projects require a "multi-level perspective" (Bliese \& Jex, 1999, p. 2) investigation. The example project used to illustrate aspects of the CCM in this paper (Knight, 2008) was designed to investigate user perceptions of information quality and the relationship between those perceptions and user decision making processes while retrieving information from the Web (Knight, 2008, 2011). The complexity required the adoption and fusion of multiple methodological strategies, including the following:

- Development of context(s) of exploration;

- Design of data collection tools which would enable the researcher to obtain multiple levels of data;

- Building of multiple constructs which adequately conceptualised the objects and context of investigation;

- Detection and conceptualising of multiple relationships between the built constructs;

- Infusion of known (i.e., previously used) theoretical constructs into the investigation of the new constructs;

- Rigorous comparison of findings in the constructed objects and relationships with previous research and theory;

- Confirmation/disconfirmation of current theory (deductive), and the proposal of novel theory (inductive).

The methodological strategies listed were implemented in the context of the specific research tasks illustrated in Figure 4, which presents a holistic and cyclical approach to the tasks associated with the research project. The project is holistic because the entire project is contextually driven. It is cyclical because each research task (1) builds on the knowledge and constructs developed in previous task(s), (2) provides pathways of feedback that can help develop the previous and future task(s) further, and (3) iteratively adds to the increasing complexity of the whole research project.

The task of literature review is a case in point. Usually coming at the beginning of a research project (a noted exception to this is in the original Grounded Theory (GT) (see Glaser \& Strauss, 1967 and Glaser, 1978) where early literature review is not advised), the literature review helps 
to establish the researcher's developing knowledge of the research object and context. As the researcher cognitively engages associated academic theory, a foundation is laid for the first constructions of any theory and research questions. These in turn further influence multiple directions of subsequent literature review, which may become broader or more narrow in scope. Literature examples in relation to methodology and design are sought when developing data collection tools and revisited again when the researcher begins data collation or classification tasks. This helps to ensure the classification structures constructed to organise, collate, and/or categorise user data are conceptually valid and consistent with previous theory. Finally, previous literature can be engaged again in relation to findings of the research. It should be noted that iteratively revisiting literature is indicated in numerous heuristic research models (see Charmaz, 1995, 2000; Eisenhardt, 1989; Strauss \& Corbin, 1994). The CCM makes the iterative nature of the relationship highly explicit (see Figure 4). In addition, the CCM also shows that the relationship can work in non-heuristic research.
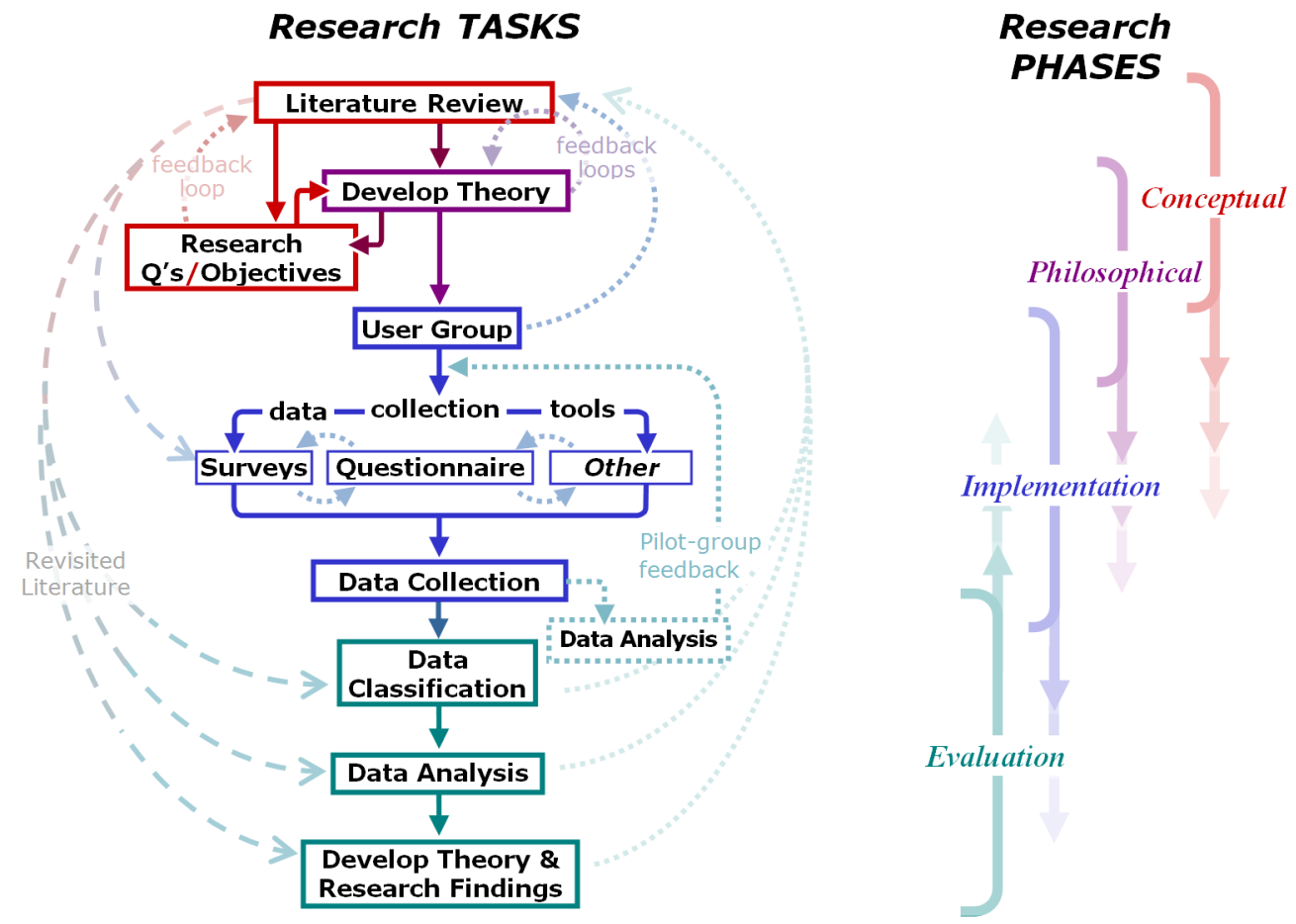

Figure 4. A Holistic (Cyclical) Approach to Research Tasks, driven by the CCM

\section{Research design: Rules of data engagement}

Conceptually separating where research methodology ends and where research design begins is a difficult proposition: (1) both constructs can be described as driving the other at various stages of the research process, and (2) different authors mean different things (conceptually) when they use either of these research terms. The term 'methodology' is being used in the current paper to describe the procedural methodological strategies adopted to investigate the phenomena of the research, rather than a broad 'research approach'. More often than not 'methodology' is framed in the literature in terms of the overall strategy of investigation, and research design is usually described as the specific techniques employed for data collection (see Hayslett \& Wildemuth, 2004; Ilieva, Baron, \& Healey, 2002; Kitchenham \& Pfleeger, 2002; Knapp \& Kirk, 2003; Yin, 1989). It is helpful then, at least at a conceptual level, to see research methodology in terms of overall adopted strategies and research design as determining the 'rules of engagement' between the researcher and the data they collect and analyse. 
A second note of caution: while defining research methodology and design as separate entities within a whole research model simplifies them enough for the novice researcher to more easily consider their methodological choices, there is always the risk that this is done at the expense of the researcher truly coming to terms with the fluid and iterative nature of their relationship.

Data collection strategies are often described as being either "quantitative" or "qualitative", the delineation being made to describe the type of data collected, i.e., quantitative data vs. qualitative data. A typical example of quantitative data might be multiple choice survey results, which can be categorised statistically according to the subsets of the investigated phenomena. Qualitative data, on the other hand, might be users' long-answers, usually in their own words, typically gathered using a questionnaire or semi-structured interview process. The trouble with naming data in such explicit terms is a good example of the problem discussed previously regarding the implications of polarised scientific vocabularies. Simply put, calling data "quantitative data" implies it should be quantitatively analysed and, conversely, that qualitative data should be qualitatively analysed. The problem is quantitative or qualitative data are not necessarily representative of the methodology used for data analysis. For example, it is possible to qualitatively analyse quantitative data, and the application of the CCM presented in this paper is an example of such an approach. How this occurred, that is - the specific rules of data engagement that governed both data collection and data analysis within the project, and described above in terms of 'research design' - will be discussed in detail in the following section.

Figure 5 is a schematic representation of the rules of engagement between some of the CoI's and the relationships between them associated with Knight's (2008) dissertation. In this sort of design, a concepts such as 'cognitive style' can be a construct to be investigated (CoI) in the context of whole user-group results, and/or its sub-constructs can be used as the 'units-of-analysis' (UoA) in the investigation of other constructs such as 'self-efficacy', 'motivation', or 'self-confidence'. The schematic demonstrates how data sets can be cross-analysed with other constructed data-sets within the research to develop a rich-picture of the investigated phenomena. As a means of data analysis, this not unlike the "constant comparison" (Mills, Bonner, \& Francis, 2006a, 2006b) techniques used in GT methodology (Glaser \& Strauss, 1967; Strauss \& Corbin, 1994) although in the CCM some contextual constructs are able to exist early enough in the research process to inform data-collection design, a strategy typically associated with quantitative, theory-testing research.

From the example shown as Figure 5, user information retrieval behaviour is able to be analysed in terms of such constructs as gender or cognitive style. Cognitive style had been conceptualised in terms of users' preferred search engine query formation - in line with previous theory and studies (see Ford, Miller, \& Moss, 2001, 2005; Frias-Martinez, Chen, \& Liu, 2007; Moss \& Hale, 1999; Palmquist \& Kim, 2000; Workman, 2004). Users were shown examples of search engine strategies and asked to select their preferred initial strategies. From the results, users were classified as either Keywords Searchers (who identified they most often used multiple keywords as their initial search query strategy), Phrase Searchers (who identified they most often used a phrase in quotation marks as their first search engine strategy), or Boolean Searchers (who used the boolean strategies so often associated with early library IR systems). User results were then examined in the context of users' cognitive style classification, with results further examined for possible existent relationships with other constructs such as user confidence, motivation, or selfefficacy. Many constructs were able to be examined in relation to which direction a relationship between them might exist and new questions constructed to better understand patterns in the data. For example, does the degree of confidence a user possesses impact on his or her motivation to engage a specific behaviour, or does motivation to engage the behaviour have a causal relationship with user confidence? 


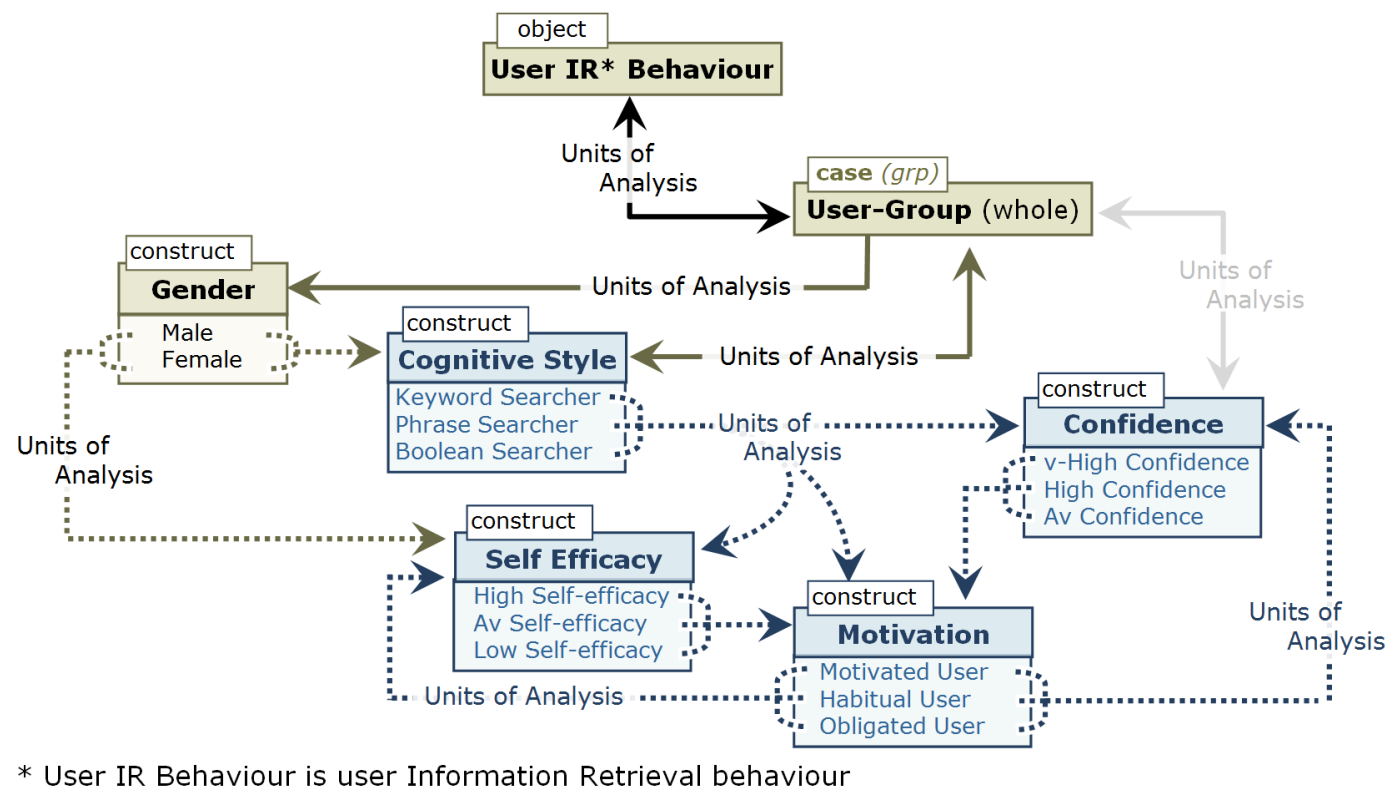

Figure 5. Research constructs, 'group-cases' and 'units-of-analysis' (schematic)

Significantly, the data-engagement represented schematically in Figure 5 would be equally comfortable in a study designed to deductively test proposed hypothesis or to inductively build possible theory, further indicating that CCT/CCM is not so much a research method, but a model for conceptualising a complex research project. In the case of the research which drove the development of the CCM (Knight, 2008) the process became an inductive theory building exercise since (1) no proposed hypothesis was being tested - although confirmation of previous theory was inevitable - and (2) the theoretical constructs used to cluster and analyse results were only partially determined previous to survey design and data collection. In addition, the constant comparison methods used in the GT (Glaser, 1978; Glaser \& Strauss, 1967) heuristic model was used to conceptualise 'previous theory' as a data-set to classify multiple CoI's in the same way they might be used to classify a conversation from a semi-structured interview. Previous theory findings were constantly engaged in an effort to understand the patterns emerging from the subsets of data.

\section{Evaluation Phase: Analysing the Data \& Writing Findings}

\section{Data analysis}

Data analysis in the CCM is based on an intuitive approach to observing, analysing, and comparing research data. Researcher intuition, as a means for developing the logic of an investigation, has been most often associated with triangulated research strategies (Dooley, 2002; Jick, 1979), but is also deeply rooted in the 'thought experiment' posing of hypothetical questions (Kuhn, 1963, 1970).

A second characteristic of data analysis in the CCM is that the 'data' to be examined are not presupposed to be only the user-results but can be conceptualised from previous theory, observations from other sources, analysis notes, and the combining of data-sets into new constructed categories. This is consistent with other heuristic methods such as the second version of GT (Strauss \& Corbin, 1994) and the co-construction of meaning between the researcher and subject in Constructivist GT (Charmaz, 2000, 2006). This approach to developing findings from the data is simple and logical, encapsulating Watt's (2007) contention that data can gradually transform itself into findings since "analysis takes place throughout the entire research process" (p.95). In addition, and contrary to what might be expected, this type of approach can be applied to both quanti- 
tative and qualitative data, in that CoI's and UoA's can be conceptualised at any stage of the research process, the analysis of which can be about testing or building theory, or both.

\section{Critical Reflection: Describing results \& findings}

The emphasis of the CCM's approach to data analysis and the describing of results/findings is, firstly, to help researchers begin to transform their data into actual results (Watt, 2007), that is, begin to understand what they are observing in their data and results, and, secondly, to help researchers begin to articulate their findings to their potential audience, and so ready themselves to begin publishing their research. The intuitive, gradual data-analysis (Eisenhardt, 1989) approach of the CCM is illustrated in Figure 6. It should be noted that the process necessitates dealing with one constructed phenomenon at a time and is proposed to involve using the following strategies:

Description of results: The writing of clear and concise descriptions of the observation made of data in the context of a constructed entity/phenomenon. Descriptions are written in the form of a discussion of the observations in the context of (a) previous theory and (b) the researcher's knowledge of the phenomena being investigated. If qualitative data - such as user narratives, or semi-structured interviews - has been used, short descriptive statements of what participants have said is a particularly effective way to contain participants' thoughts into a similar vocabulary, that is, the vocabulary of the researcher, since participants will not only use different expressions and phrases to each other, they can use similar phrases to mean different things. Some cross analysis may take place as the researcher begins to discuss subsequent constructed entities, but usually as a connection to writing short descriptions of observations relating to another classified construct/phenomenon in the research.

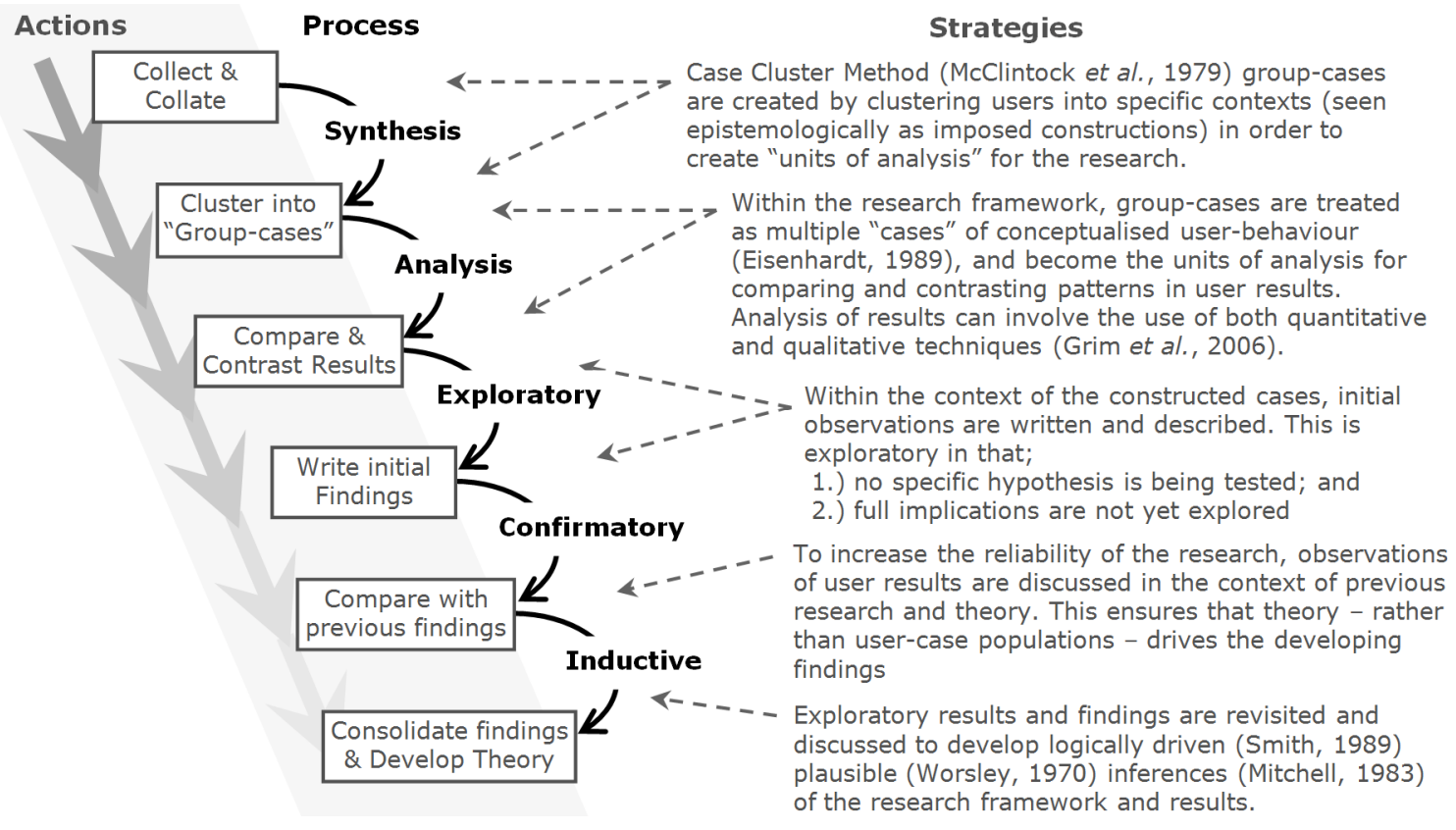

Figure 6. Data Analysis Strategies

Preliminary hypothesis generation/confirmation: Preliminary findings, recorded and discussed during the observation and discussion of specific phenomenon, analysis of, or cross-analysis between, user results data. The two suppositions of this strategy are (1) the recorded preliminary findings need not be considered exhaustive and (2) provided enough analytical thought goes into each "observations" discussion, a rich picture can slowly develop of the phenomena being investigated as new preliminary findings are made and some findings repeated in subsequent discus- 
sions. Significantly, preliminary findings discussions do not, and should not, become full arguments for the findings they record. In other words, at this early stage the researcher does not try to understand the 'why' of their results. This helps to address the natural human-inquiry tendency to begin 'reading' results into the data being observed, analysed, and described. The emphasis, then, is on the process of an exploration of results, with preliminary findings directly reflecting the observations and analysis just made. Comparisons can be made at this point with previous literature or where the researcher has encountered this type of data/result in the past; this will help with the later analysis of any significant results and/or findings.

Recording observed limitations: In the same way that preliminary findings are written in the context of where/when they are observed, limitations are also recorded in context of where/when they are encountered. The assumption here is that specific limitations of the research are often first encountered during the analytical process, where anomalies may be found or confirmed during the description of results. The recording of these noted limitations in the context in which they are encountered provides a useful tool for understanding how those limitations may have impacted on localised results and, secondly, provides a record of issues, particularly if similar limitations are encountered in subsequent description of results.

Developing hypotheses (theory building): Preliminary findings found to be relevant to research questions - which represent the identified research problem being addressed - are now revisited and built into research hypotheses. Hypothesis generation and development takes place from a big-picture view-point as the researcher revisits multiple findings statements, written as the observations were being made and discussed. With specific limitations already addressed and findings already established, the growing knowledge and skill of the researcher is now utilised as an exploration and discussion of multiple findings in the context of the original research questions. Importantly, these antecedents to the final development of research hypotheses have been built piece by piece without the researcher feeling pressured to develop the findings per se. Multiple findings-type statements can be compared and contrasted, with only those relevant to the research questions being fully discussed. Implied in this, however, is that accidental (or emergent) - yet significant - findings, not necessarily relevant to the original research questions, can also be discovered.

\section{Contributions, Limitations \& Future Research}

\section{Contributions}

The CCM and its associated theory contribute to the discourse of scientific methodology theory in a number of ways.

\section{An intuitive approach to research inquiry}

The CCM offers a robust intuitive model for scientific investigation, where context and constructs are used to conceptualise both the process and the object of the research rather than the traditional notions of quantitative versus qualitative research, which are relegated to the position of strategies of investigation, chosen according to what is appropriate for the research at large. This paper contends that the model can be used to conceptualise both deductive hypothesis testing and inductive theory building, pushing the positivist researcher to consider the philosophical assumptions of their hypothesis being tested and the interpretivist researcher to consider the constructed validity of their theory building.

Pragmatically, using process-models to help guide the researcher through the complex process of research conceptualisation and design, the model provides a theoretical framework by which a researcher is able to recognise his/her philosophical assumptions of the research object(s) and 
how those assumptions impact the conceptual validity of their research inquiry. In addition, the holistic, iterative approach (see Figure 4) demonstrates how the ongoing processes and tasks involved in a complex research project can be used to continually improve and strengthen the research as a whole.

\section{Innovative in "systemics" application}

As emergent inter-disciplinary and trans-disciplinary fields such as cybernetics and digital ecosystems (Fiorina, 2006) and significant new developments in the epistemological framing of systems theory (Knight \& Halkett, 2010; Olsson, 2004) begin to filter through to IS/IT related disciplines, the CCM offers a systems-driven and contextual approach to developing research methodology and design. The process of considering both the research objects (constructs) and their relationships (context) makes the CCM ideal for investigating Complexity (Waldrop, 1992); Living Systems (Miller, 1978; Miller \& Miller, 1995) and Complex Systems (Bunge, 1979); as well as Complex Adaptive Systems (Holland, 1992) Artificial Intelligence (Loosemore, 2007), and multidimensional phenomena.

\section{Limitations \& Future Research}

\section{Limitations}

The CCM, and the CCT which drives it, are still relatively young in their evolution. The result is that their self-justifying argument requires additional research project application before it can be considered a cohesive, theoretically sustainable, research model. However, the approach has thus far been substantiated as the research framework behind numerous published research articles since 2005 (see for example Knight, 2011; Knight \& Burn, 2005, in press; Knight \& Spink, 2008).

A second limitation relates to the lack of space in any journal article to discuss a model which probably requires a book to be fully fleshed out and considered. The authors acknowledge that the original project which drove the development of the CCM/CCT (see Knight, 2008) could not be discussed at length in the space provided, which would have facilitated a far more detailed discussion and analysis of the novel model proposed. Instead, this article introduces the arguments for the over-riding supposition of the 'contextual' and 'constructed' nature of Contextual Construct Theory (CCT) and Model (CCM), provides a general discussion of what's involved in the research approach, and so demonstrates how a model of this nature can be used to conceptualise and guide a scientific investigation.

\section{Future research \& application}

The CCM, and the CCT that drives it, offers some innovative avenues for methodological theory exploration, particularly in relation to how contextual and complex systems-thinking is being applied within multiple research disciplines. Its emphasis on the (1) research constructs created and (2) conceptualisation of their relational context provides a platform for investigating the multiple constructs and complex areas of scientific analysis in a post-modern world. The old deductive, reductionist methods of isolating phenomena and limiting variables and relationships to create a predictable environment of investigation offer limited insight into many complex real-world scenarios, which are "systemic and cannot be understood or resolved in isolation" (Hammond, 2002, 430). A methodology which will allow for the conceptualisation of both research constructs and their context, then, may offer a new way forward.

At a time when the information systems discipline is going through what its leading authors have described as an "identity crisis" (Benbasat \& Zmud, 2003) there has never been a greater need for 
IS researchers to consider their methodological options. Benbasat \& Zmud (2003) contended the ever increasingly "eclectic" nature of both the practice and study of IS calls for multiple paradigms and approaches when researching information science driven phenomena. The CCT/CCM represents one of the first pragmatic research methodology models to emerge from the field of information systems/science. While it represents a deviation from the more common deductivedriven research associated with the IS discipline, this should not deter IS researchers from pushing the discipline, methodologically speaking, into uncharted waters.

\section{Conclusion}

This paper has presented a novel research model, Contextual Constructs Model, which is theoretically driven by the assumption that research involves two inter-related components: that of (1) context and (2) cognitively built constructs. At a theoretical level, the CCT contends that research objects, or phenomena, are scientifically conceptualised constructs, described in terms of vocabularies, which possess a co-dependent relationship with the context in which they are investigated. Moreover, the CCM itself is seen as a manifestation of the theory (CCT) which drives it, where 'research' itself is recognised as a constructed concept, in the context of an investigative process.

At a pragmatic, operational level, the CCM can be used to identify the (1) Conceptual, (2) Philosophical, (3) Implementation, and (4) Evaluation phases and tasks associated with a complex research project and has been shown to be suitable for the development of multiple methodological approaches to scientific research.

\section{Acknowledgements}

This research comes from the award winning dissertation" "User Perceptions of Information Quality in World Wide Web Information Retrieval Behaviours" which was funded by the Australian Research Council as part of the ARC-Discovery Project DP0452862: "Building an Internet Search Engine for Quality Information Retrieval" - a partnership between the ARC, Edith Cowan University and the University of Wollongong (2005-2008). The authors thank Professor Janice Burn (retired) for her invaluable contributions to this research between 2005 and 2008 and Professor Yair Levy for his editing and in-put with later drafts.

* The dissertation won the "2008 Ballou \& Pazer DQ/IQ Dissertation of the Year" awarded annually at MIT's ICIQ for "the dissertation that demonstrates the most significant contribution to the information quality field"

\section{References}

Alvesson, M., \& Sandberg, J. (2011). Generating research questions through problematization. The Academy of Management Review, 36(2), 247-271.

Amaratunga, D., Baldry, D., Sarshar, M., \& Newton, R. (2002). Quantitative and qualitative research in the built environment: Application of "mixed" research approach. Work Study, 51(1), 117-131. doi: $10.1108 / 00438020210415488$

Benbasat, I., \& Zmud, R. W. (2003). The identity crisis within the IS discipline: Defining and communicating the discipline's core properties. MIS Quarterly, 29(2), 183-194.

Bliese, P. D., \& Jex, S. M. (1999). Incorporating multiple levels of analysis into occupational stress research. Work \& Stress, 13(1), 1-6. doi: 10.1080/026783799296147

Buckley, J. W., Buckley, M. H., \& Ching, H. F. (1976). Research methodology and business decisions. New York, NY: National Association of Accountants.

Bunge, M. (1979). A world of systems. Dordrecht \& Boston, MA: Reidel Publishing. 
Cecez-Kecmanovic, D. (2001). Doing critical IS research: The question of methodology. In E. Trauth (Ed.), Qualitative research in IS: Issues and trends (pp. 141-162). Hershey, PA: Idea Group Publishing.

Charmaz, K. (1995). Grounded theory. In J. A. Smith, R. Harre, \& L. V. Langenhove (Eds.), Rethinking methods in psychology (pp. 29-49). London: Sage.

Charmaz, K. (2000). Grounded theory: Objectivist and constructivist methods. In N. Denzin \& Y. Lincoln (Eds.), Handbook of qualitative research (pp. 509-535). Thousand Oaks, CA: Sage.

Charmaz, K. (2006). Constructing grounded theory: A practical guide through qualitative analysis. Sage Publications.

Christie, M., Rowe, P., Perry, C., \& Chamard, J. (2000). Implementation of realism in case study research methodology. Paper presented at the International Council for Small Business, Annual Conference, Brisbane, Australia.

Collier, A. (1994). Critical realism: An introduction to the philosophy of Roy Bhaskar. London, UK: Verso.

Das, T. H. (1983). Qualitative research in organisational behaviour. Journal of Management Studies, 20(3), 301-314. doi: 10.1111/j.1467-6486.1983.tb00209.x

Davis, F. D. (1989). Perceived usefulness, perceived ease of use, and user acceptance of information technology. MIS Quarterly, 13(3), 319-339.

Denzin, N. K. (1978). The research act: A theoretical introduction to sociological methods. New York: McGraw-Hill

Dey, C. (2002). Methodological issues: The use of critical ethnography as an active research methodology. Accounting, Auditing \& Accountability Journal, 15(1), 106-121. doi: 10.1108/09513570210418923

Dobson, P. J. (2002). Critical realism and information systems research: Why bother with philosophy? Information Research, 7(2), 124. Available at http://informationr.net/ir/7-2/paper124.html

Donham, J., Heinrich, J. A., \& Bostwick, K. A. (2009). Mental models of research: Generating authentic questions. College Teaching, 58(1), 8-14. doi: 10.1080/87567550903252835

Dooley, L. M. (2002). Case study research and theory building. Advances in Developing Human Resources, 4(3), 335-354. doi: 10.1177/1523422302043007

Eisenhardt, E. M. (1989). Building theories from case study research. Academy of Management Review, 14(4), 532-550.

Ellis, T. J., \& Levy, Y. (2008). Framework of problem-based research: A guide for novice researchers on the development of a research-worthy problem. Informing Science Journal: The International Journal of an Emerging Transdiscipline, 11, 17-33. Retrieved from http://www.inform.nu/Articles/Vol11/ISJv11p017-033Ellis486.pdf

Ellis, T. J., \& Levy, Y. (2009). Towards a guide for novice researchers on research methodology: Review and proposed methods. Issues in Informing Science and Information Technology, 6, 323-337. Retrieved from http://iisit.org/Vol6/IISITv6p323-337Ellis663.pdf

Fielden, K. (2003). Fact or fiction: Qualitative research results in information systems. Paper presented at InSITE '03, Auckland, New Zealand.

Fiorina, C. (2006). The digital ecosystem. Hewlett Packard.

Ford, N., Miller, D., \& Moss, N. (2001). The role of individual differences in Internet searching: An empirical study. Journal of the American Society for Information Science and Technology, 52(12), 10491066. doi: 10.1002/asi.1165

Ford, N., Miller, D., \& Moss, N. (2005). Web search strategies and human individual differences: Cognitive and demographic factors, Internet attitudes, and approaches. Journal of the American Society for Information Science and Technology, 56(7), 741-756. doi: 10.1002/asi.20168 
Frias-Martinez, E., Chen, S. Y., \& Liu, X. (2007). Automatic cognitive style identification of digital library users for personalization. Journal of the American Society for Information Science and Technology, 58(2), 237-251. doi: 10.1002/asi.20477

Galliers, R. D. (1992). Choosing information systems research approaches. In R. D. Galliers (Ed.), Information systems research: Issues, methods and practical guidelines. Oxford: Blackwell Scientific.

Geertz, C. (1973). Thick description: Toward an interpretive theory of culture. New York, NY: Basic Books.

Gergen, K. J. (1999). An invitation to social construction. London: Sage.

Glaser, B. G. (1978). Theoretical sensitivity: Advances in the methodology of grounded theory. Mill Valley, CA: Sociology Press.

Glaser, B. G., \& Strauss, A. (1967). The discovery of grounded theory: Strategies of qualitative research. London: Wiedenfeld and Nicholson.

Goulding, C. (2002). Grounded theory: A practical guide for management, business and market researchers. London: Sage.

Greene, J. C., \& Caracelli, V. J. (2003). Making paradigmatic sense of mixed methods practice. In A. Tashakkor \& C. Teddue (Eds.), Handbook of mixed methods in social and behavioral research (pp. 91110). Thousand Oaks, CA: Sage.

Hammond, D. (2002). Exploring the genealogy of systems thinking. Systems Research and Behavioral Science, 19(5), 429-439. doi: 10.1002/sres.499

Hammond, D. (2003). The science of synthesis: Exploring the social implications of general systems theory. Colorado: University Press of Colorado.

Hayslett, M., \& Wildemuth, B. (2004). Pixels or pencils? The relative effectiveness of Web-based versus paper surveys. Library \& Information Science Research, 26(f1), 73-93. doi: 10.1016/j.lisr.2003.11.005

Heinström, J. (2003). Five personality dimensions and their influence on information behaviour. Information Research, 9(1). Retrieved from http://informationr.net/ir/9-1/paper165.html

Holden, M. T., \& Lynch, P. (2004). Choosing the appropriate methodology: Understanding research philosophy. The Marketing Review, 4(4), 397-409. doi: 10.1362/1469347042772428

Holland, J. H. (1992). Complex adaptive systems. Daedalus, 121(1), 17-30.

Ilieva, J., Baron, S., \& Healey, N. M. (2002). Online surveys in marketing research: Pros and cons. International Journal of Market Research, 44(3), 361-382.

Janesick, V. (2000). The choreography of qualitative research design: Minuets, improvisations, and crystallization. In N. K. Denzin \& Y. S. Lincoln (Eds.), The handbook of qualitative research (pp. 379-400). Thousand Oaks, California: Sage.

Jick, T. D. (1979). Mixing qualitative and quantitative methods: Triangulation in action. Administrative Science Quarterly, 24, 602-611.

Jonassen, D. H. (1991). Objectivism versus constructivism: Do we need a new philosophical paradigm? Educational Technology Research and Development, 39(3), 5-14. doi: 10.1007/BF02296434

Kaplan, B., \& Duchon, D. (1988). Combining qualitative and quantitative methods in information systems research: A case study. MIS Quarterly, 12(4), 571-586.

Kari, J. (2004). Web information seeking by pages. World Wide Web, information seeking, personal development, navigation. Information Research, 9(4). Retrieved from http://InformationR.net/ir/94/paper183.html

Kaufman, S. A. (1992). Origins of order: Self organization and selection in evolution. Oxford: Oxford University Press. 
Kerlinger, F. N., \& Lee, H. B. (2000). Foundations of behavioral research. Holt, NY: Harcourt College Publishers.

Kitchenham, B. A., \& Pfleeger, S. L. (2002). Principles of survey research part 2: Designing a survey. ACM Software Engineering Notes (SIGSOFT), 27(1), 18-20.

Knapp, H., \& Kirk, S. A. (2003). Using pencil and paper, Internet and touch-tone phones for selfadministered surveys: Does methodology matter? Computers in Human Behavior, 19(1), 117-134. doi: 10.1016/S0747-5632(02)00008-0

Knight, S. A. (2008). User perceptions of information quality in World Wide Web information retrieval behaviours. PhD Dissertation, School of Management Information Systems, Edith Cowan University, Perth Western Australia

Knight, S. A. (2011). The combined conceptual life cycle model of information quality in user perceptions of IQ on the Web. Paper presented at the 16th International Conference on Information Quality, Adelaide, 18-20 Nov.

Knight, S. A., \& Burn, J. M (2005). Developing a framework for assessing information quality on the World Wide Web. Informing Science Journal: The International Journal of an Emerging Transdiscipline, 8(5), 159-172. Retrieved from http://www.inform.nu/Articles/Vol8/v8p159-172Knig.pdf

Knight, S. A., \& Burn, J. M. (in press). A preliminary introduction to the OTAM: Exploring users' perceptions of their on-going interaction with adopted technologies. Australasian Journal of Information Systems.

Knight, S. A., \& Halkett, G. K. B. (2010). Living systems, complexity \& information systems science. Paper presented at the Australasian Conference in Information Systems (ACIS-2010), Brisbane, Australia.

Knight, S. A., Halkett, G. K., \& Cross, D. (2010). The context and contextual constructs of research. Paper presented at the Qualitative Research in IT \& IT in Qualitative Research (QualIT-2010) Conference, Brisbane, Australia.

Knight, S. A., \& Spink, A. H. (2008). Toward a Web search information behavior model. In A. Spink \& M. Zimmer (Eds.), Web search: Multidisciplinary perspectives (pp. 209-234). Berlin: Springer.

Krauss, S. E. (2005). Research paradigms and meaning making: A primer. The Qualitative Report, 10(4), 758-770.

Krieger, S. (1991). Social science and the self: Personal essays on an art form. New Brunswick: Rutgers University Press.

Kuhn, T. S. (1963). A function for thought experiments. In R. Taton \& I. B. Cohen (Eds.), Melanges Alexandre Koyre. Paris: Hermann.

Kuhn, T. S. (1970). The structure of scientific revolutions. Chicago: University of Chicago Press.

Landry, M., \& Banville, C. (1992). A disciplined methodological pluralism for MIS research. Accounting, Management and Information Technology, 2(2), 77-97. doi: 10.1016/0959-8022(92)90002-A

Lee, A. S. (1989). A scientific methodology for MIS case studies. MIS Quarterly, 13(1), 33-50.

Lee, A. S. (1991). Integrating positivist and interpretive approaches to organizational research. Organization Science, 2(4), 342-365.

Leonard, N. H., Scholl, R. W., \& Kowalski, K. B. (1999). Information processing style and decision making. Journal of Organizational Behavior, 20(3), 407-420. doi: 10.1002/(SICI)1099-1379(199905)

Levy, Y., \& Ellis, T. J. (2006). A systems approach to conduct an effective literature review in support of information systems research. Informing Science Journal, 9, 181-212. Retrieved from http://www.inform.nu/Articles/Vol9/V9p181-212Levy99.pdf

Loosemore, R. (2007). Complex systems, artificial intelligence and theoretical psychology. Frontiers in Artificial Intelligence and Applications, 157, 159-173. 
Mathison, S. (1988). Why triangulate? Educational Researcher, 17(2), 13-17. doi: 10.3102/0013189X017002013

McClintock, C. C., Brannon, D., \& Maynard-Moody, S. (1979). Applying the logic of sample surveys to qualitative case studies: The case cluster method. Administrative Science Quarterly, 24(4), 612-629.

Miller, J. G. (1978). Living systems. New York: McGraw-Hill.

Miller, J. G., \& Miller, J. L. (1995). Applications of living systems theory. Systemic Practice and Action Research, 8(1), 19-45. doi: 10.1007/BF02249174

Mills, J., Bonner, A., \& Francis, K. (2006a). Adopting a constructivist approach to grounded theory: Implications for research design. International Journal of Nursing Practice, 12, 8-13. doi: 10.1111/j.1440172X.2006.00543.X

Mills, J., Bonner, A., \& Francis, K. (2006b). The development of constructivist grounded theory. International Journal of Qualitative Methods, 5(1), 25-35.

Mingers, J. (2001a). Combining IS research methods: Towards a pluralist methodology. Information Systems Research, 12(3), 240-259. doi: 10.1287/isre.12.3.240.9709

Mingers, J. (2001b). Embodying information systems: The contribution of phenomenology. Information and Organization, 11(2), 103-128. doi: 10.1016/S1471-7727(00)00005-1

Modell, S. (2005). Triangulation between case study and survey methods in management accounting research: An assessment of validity implications. Management Accounting Research, 16(2), 231-254. doi: 10.1016/j.mar.2005.03.001

Moss, N., \& Hale, G. (1999). Cognitive style and its effect on Internet searching: A quantitative investigation. European Conference on Educational Research (ECER '99), p. 1189. Finland.

Myers, M. (1997). Qualitative research in information systems. MIS Quarterly, 21(2), 241-242.

Newton, I. (1687). Philosophice naturalis principia mathematica (Mathematical principles of natural philosophy). London: UK

Olesen, V. L. (2000). Feminisms and qualitative research at and into the millennium. In N. K. Denzin \& Y. S. Lincoln (Eds.), The handbook of qualitative research (pp. 215-256). Thousand Oaks, California: Sage.

Olsson, M. O. (2004). Schools of systems thinking - Development trends in systems methodology. In M. O. Olsson \& S. Gunnar (Eds.), Systems approaches and their application (pp. 31-74). Springer.

Onwuegbuzie, A. J., \& Leech, N. L. (2005). Taking the "Q" out of research: Teaching research methodology courses without the divide between quantitative and qualitative paradigms. Quality \& Quantity: International Journal of Methodology, 39, 267-296. doi: 0.1007/s11135-004-1670-0

Onwuegbuzie, A. J., \& Teddlie, C. (2003). A framework for analysing data in mixed methods research. In A. Tashakkori \& C. Teddlie (Eds.), Handbook of mixed methods in social and behavioural research (pp. 351-383). Thousand Oaks, CA: Sage.

Orlikowski, W. J., \& Baroudi, J. J. (1991). Studying information technology in organizations: Research approaches and assumptions. Information Systems Research, 2(1), 1-28.

Pandit, N. R. (1996). The creation of theory: A recent application of the grounded theory method. The Qualitative Report, 2(4).

Palmquist, R. A., \& Kim, K.-S. (2000). Cognitive style and on-line database search experience as predictors of Web search performance. Journal of the American Society for Information Science and Technology, 51(6), p.558-566. doi: 10.1002/(SICI)1097-4571(2000)

Pather, S., \& Remenyi, D. (2004). Some of the philosophical issues underpinning research in information systems: from positivism to critical realism. Paper presented at the Annual Research Conference of the South African institute of Computer Scientists \& Information Technologists on IT Research in Developing Countries, Stellenbosch, South Africa. 
Presbury, R., \& Fitzgerald, A. (2006). Using a kaleidoscope in research: An example of how triangulation is used to undertake management research. Paper presented at the Social Science Methodology Conference, University of Sydney, Australia.

Ramsay, J. (1998). Problems with empiricism and the philosophy of science: Implications for purchasing research. European Journal of Purchasing and Supply, 4(2/3), 163-173. doi: 10.1016/S09697012(97)00024-5

Remenyi, D., Williams, B., Money, A., \& Swartz, E. (1998). Doing research in business and management. London: Sage Publications.

Rosenberg, A. (1993). Hume and the philosophy of science. In D. Norton (Ed.), The Cambridge companion to Hume (pp. 64-89). New York: Cambridge University Press.

Rowley, J. (2002). Using case studies in research. Management Research News, 25(1), 16-27. doi: $10.1108 / 01409170210782990$

Sandberg, J., \& Alvesson, M. (2011). Ways of constructing research questions: Gap-spotting or problematization? Organization, 18(1), 23-44. doi: 10.1177/1350508410372151

Schostak, J. (2002). Critiquing critical realism: A working paper. Paper presented at the European Conference on Educational Research (ECER 2002), Portugal. Retrieved from http://www.enquirylearning.net/ELU/Issues/Research/Critical\%20Realism.htm

Schutz, A., Walsh, G., \& Lehnert, F. (1972). The phenomenology of the social world. London, UK: Heinemann Educational.

Senge, P. (2006). The fifth discipline: The art \& practice of the learning organization. Retrieved from $\mathrm{http} / / / \mathrm{www} \cdot$ randomhouse.com/doubleday/currency/catalog/display.pperl?isbn=9780385517256\&view $=$ excerpt

Seymour, G. E. (2006). Systems thought in psychology. Retrieved from http://www.linking.to/PSY8412/Systems_Thought_in_Psychology.doc

Slater, S. F., \& Atuahene-Gima, K. (2004). Conducting survey research in strategic management. Research Methodology in Strategy and Management, 1, 227-249. doi: 10.1016/S1479-8387(04)01108-7

Sonnenwald, D. H., \& Iivonen, M. (1999). An integrated human information behavior research framework for information studies. Library \& Information Science Research, 21(4), 429-457. doi: 10.1016/S07408188(99)00023-7

Stahl, B. C. (2005). A critical view of the ethical nature of interpretive research: Paul Ricceur and the other. Paper presented at the 13th European Conference on Information Systems, Regensburg, Germany, 26 to 28 May 2005.

Strauss, A., \& Corbin, J. (1994). Grounded theory methodology: An overview. In N. K. Denzin \& Y. S. Lincoln (Eds.), Handbook of qualitative research (pp. 273-285). Thousand Oaks, CA: Sage.

Tashakkori, A., \& Creswell, J. (2007). Editorial: Exploring the nature of research questions in mixed methods research. Journal of Mixed Methods Research, 1(3), 207-211. doi: 10.1177/1558689807302814

Thurmond, V. (2001). The point of triangulation. Journal of Nursing Scholarship, 33(3), 253-258. doi: 10.1111/j.1547-5069.2001.00253.x

Trauth, E. (2001). The choice of qualitative methods in IS research. In E. Trauth (Ed.), Qualitative research in IS: Issues and trends. Idea Group Publishing.

Trochim, W. M. (2002). The research methods knowledge base (2nd ed.). Retrieved August 16, 2004, from http://trochim.human.cornell.edu/kb/index.htm

von Bertalanffy, L. (1950). An outline for general systems theory. British Journal for the Philosophy of Science, $1(2)$.

Waldrop, M. M. (1992). Complexity: The emerging science at the edge of order and chaos. New York. 
Wang, R. Y., \& Strong, D. M. (1996). Beyond accuracy: What data quality means to data consumers. Journal of Management Information Systems, 12(4), 5-34.

Watt, D. (2007). On becoming a qualitative researcher: The value of reflexivity. The Qualitative Report, $12(1), 82-101$.

Webster, J., \& Watson, R. T. (2002). Analysing the past to prepare for the future. Writing a literature review. MIS Quarterly, 26(2), xiii-xxiii.

White, A. (2007). Understanding hypertext cognition: Developing mental models to aid users' comprehension. First Monday, 12(1). Retrieved from http://firstmonday.org/issues/issue12_11/white/index.html

Williamson, K. (2006). Research in constructivist frameworks using ethnographic techniques. Library Trends, 55(1), 83-101. doi: 10.1353/lib.2006.0054

Wood, A. (2000). Hume: The problem of induction. Stanford University. Retrieved August 31, 2002, from http://www.stanford.edu/ allenw/Phil102/Hume - Induction.doc

Workman, M. (2004). Performance and perceived effectiveness in computer-based and computer-aided education: do cognitive styles make a difference? Computers in Human Behaviour, 20(4), 517-534. doi: 10.1016/j.chb.2003.10.003

Yin, R. K. (1981). The case study as a serious research strategy. Knowledge: Creation, Diffusion, Utilization, 3(1), 97-114.

Yin, R. K. (1989). Case study research design and methods. Newbury Park: Sage.

Zach, L. (2006). Using a multiple-case studies design to investigate the information-seeking behaviour of arts administrators. Library Trends, 55(1), 4-21. doi: 10.1353/lib.2006.0055

\section{Biographies}

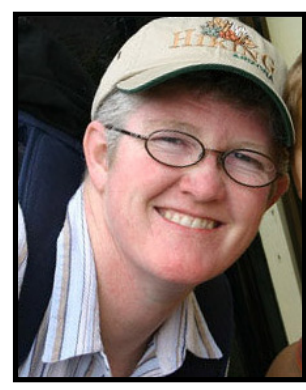

Dr Shirlee-ann Knight is a Post-doctoral Research Fellow with the Systems \& Intervention Research Centre for Health and West Australian Centre for Cancer \& Palliative Care at Edith Cowan University (ECU) Western Australia. She holds a PhD in Information Systems, and specialises in the analysis of the complex relationships existent within systems. Shirlee-ann's PhD "User Perceptions of Information Quality in World Wide Web Information Retrieval Behaviour" was funded by an Australian Research Council Discovery Project between ECU and University of Wollongong, and earned the prestigious "2008 Ballou \& Pazer DQ/IQ Dissertation of the Year" award (ICIQ at M.I.T.) for its contribution to the field of information quality research. Shirlee-ann currently works in a Health Systems context, investigating novel and innovative approaches to understanding Health ICT implementation and adoption.

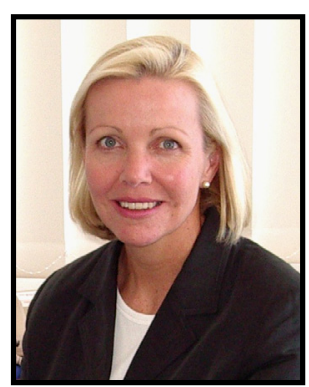

Professor Donna Cross is Professor of Child and Adolescent Health at Edith Cowan University (ECU) in Western Australia. She holds a Doctor of Education (D.Ed) from Columbia University, and has been conducting award winning applied research in Child Health for over 20 years. The recipient of over 8 million dollars (AUD) in research funding, her key research interest is youth-based health intervention research. She has conducted primary prevention and school-based intervention research principally in Australia, as well as the USA, Canada, Russia, Japan, Israel, and South Africa, working with international organisations such as the World Health Organisation (WHO), UNICEF and the American Health Foundation. Recently awarded the coveted "Western Australian of the year" for 2012 for her contribution to improving child health, Donna works tirelessly to advance research and its application to real world problems. 